\title{
RANCANG BANGUN PERALATAN PENGAMAN PADA TOKO PERHIASAN BERBASIS ARDUINO
}

\author{
Hani Dewi Ariessanti ${ }^{1}$ \\ Indrianto $^{2}$ \\ Rifan Munzilin ${ }^{3}$ \\ Email:rifan@raharja.info,hani.dewi@raharja.info,indrianto@raharja.info
}

Diterima : 06 November 2014 / Disetujui : 12 Desember 2014

\begin{abstract}
With increasing human needs in terms of security, especially in securing the jewelry store then made a design that resembles the display of safety equipment. The working principle of safety equipment on this arduino -based jewelry store is by using infrared sensors to transmit data at the next arduino electric current is converted into mechanical motion of the dc motor, the next shipment via bluetooth character code that is processed in the microcontroller into a form of decision. The method is obtainable design technique that consists of : Identify the need is to identify the needs of what is needed in the manufacture of tools, Analysis of the needs is to analyze all the needs of the tool before the tool design process, The design of the hardware and software that is designing and preparing the materials are to be used to make tools, Preparation of tools that process of unification of all materials to form tools and, Testing tools that test the performance of the tool
\end{abstract}

Keywords: Arduino, Infrared Sensor, DC motors, Bluetooth

\begin{abstract}
ABSTRAK
Dengan meningkatnya kebutuhan manusia dalam hal keamanan terutama dalam pengamanan toko perhiasan maka dibuatlah sebuah rancang bangun peralatan pengaman yang menyerupai display. Prinsip kerja peralatan pengaman pada toko perhiasan berbasis arduino ini yaitu dengan menggunakan sensor infrared untuk mengirimkan data pada arduino selanjutnya arus listrik diubah menjadi gerakan mekanis pada motor dc, selanjutnya pengiriman kode karakter melalui bluetooth yang diproses pada mikrokontroler menjadi sebuah bentuk keputusan. Adapun metode ini didapat teknik perancangan yang terdiri dari : Identifikasi kebutuhan yaitu mengenali kebutuhan apa saja yang dibutuhkan pada pembuatan alat, Analisis kebutuhan yaitu menganalisa semua kebutuhan pada alat sebelum proses perancangan alat, Perancangan perangkat keras dan perangkat lunak yaitu merancang dan mempersiapkan bahan apa saja yang digunakan untuk membuat alat, Pembuatan alat yaitu proses penyatuan semua bahan hingga membentuk alat dan, Pengujian alat yaitu menguji kinerja alat
\end{abstract}

Kata kunci : Arduino, Sensor Infrared, Motor DC, Bluetooth

\section{PENDAHULUAN}

Pesatnya perkembangan ilmu teknologi di bidang elektronika dan komunikasi sekarang ini, banyak manfaat yang bisa dirasakan oleh lapisan masyarakat, salah satunya untuk mempermudah segala macam pekerjaan di bidang industri, keamanan, pendidikan, pemerintahan dan lain sebagainya. Seiring dengan naiknya kebutuhan masyarakat dalam keamanan dan teknologi yang semakin canggih, dibuatlah suatu alat yang mampu menjaga keamanan toko perhiasan yang menyerupai display. 
Ketergantungan keamanan toko perhiasan selama ini hanya mengandalkan tenaga manusia yang dapat menyebabkan resiko besar yaitu semakin nekatnya para pencuri yang dapat menyakiti hingga sampai berakibat kemanatian pada penjaga keamanan toko tersebut. Maka dengan teknologi embbed system yang berkembang pada saat ini dibuat sebuah alat pengaman yang dapat menggantikan tugas menjaga keamanan.

\section{PERMASALAHAN}

Melihat faktor-faktor yang telah dijabarkan sebelumnya maka dapat ditarik beberapa rumusan masalah yaitu :

1) Bagaimana merancang hardware yang menyerupai display untuk mengendalikan keamanan pada toko perhiasan.

2) Bagaimana mikrokontroler dapat berkomunikasi dengan perangkat lain, seperti bluetooth dan motor dc

3) Bagaimana unjuk kerja sistem keamanan toko perhiasan, untuk itu perlunya dibuat rancang bangun peralatan pengaman berbasis arduino.

\section{LITERATURE REVIEW}

Banyaknya penelitian yang sebelumnya dilakukan mengenai peralatan pengaman ini, namu pada penelitian ini belum ada yang menggabungkan sensor infrared dan bluetooth untuk mengerakan motor dc pada display perhiasan. Beberapa Literatur Riview adalah sebagai berikut :

1. Penelitian yang dilakukan oleh Nurdansyah dari STMIK Raharja yang berjudul "HOME APPLIANCES CONTROLING WITH MOBILE DEVICE BASED ON ANDROID OS" pada tahun 2013. Penelitian ini membahas tentang pengendalian peralatan rumah menggunakan Smratphone
Android menggunakan media jaringan wireless.

2. Penelitian yang dilakukan oleh Muhammad Bintar dari Perguruan Tinggi Raharja yang berjudul "SISTEM PENGONTROLAN LAMPU MENGGUNAKAN INPUT SUARA BERBASIS ARDUINO" pada tahun 2013. Penelitian ini menjelaskan tentang pengendalian lampu menggunakan arduino dan android.

3. Penelitian yang dilakukan oleh Teguh Arif Gustaman dari Institut Teknologi Sepuluh November Surabaya yang berjudul " PENGENDALI PINTU GERBANG MENGGUNAKAN BLUETOOTH BERBASIS MIKROKONTROLLER

ATMEGA 8" pada tahun 2010. Penelitian ini menjelaskan tentang pengiriman sebuah kode karakter melalui Bluetooth.

4. Penelitian yang dilakukan oleh Herman Putra Aritonang dari STMIK LOGIKA Medan yang berjudul " MEMANFAATKAN QR CODE \& SMARTPHONE ANDROID SEBAGAI ALAT ABSENSI PEGAWAI". Penelitian ini menjelaskan tentang Qr Code sebagai identifikasi absen.

5. Penelitian yang dilakukan oleh Satriyo Budi Santoso dari Perguruan Tinggi Raharja yang berjudul "Perancangan Miniatur Palang Perlintasan Kereta API Menggunakan Infrared dan Mikrokontroller AT89S51 Pada PT.KAI pada tahun 2013.

\section{LANDASAN TEORI}

Arduino adalah kit elektronik atau papan rangkaian elektronik open source yang di dalamnya terdapat komponen utama yaitu sebuah chip mikrokontroler dengan jenis AVR 
dari perusahaan Atmel. Arduino dikatakan sebagai sebuah platform dari physical computing yang bersifat open source. Pertama-tama perlu dipahami bahwa kata "platform" di sini adalah sebuah pilihan kata yang tepat. Arduino tidak hanya sekedar sebuah alat pengembangan, tetapi kombinasi dari hardware, bahasa pemrograman dan Integrated Development Environment (IDE) yang canggih. IDE adalah sebuah software yang sangat berperan untuk menulis program, meng-compile menjadi kode biner dan meng-upload ke dalam memory microcontroller.

Menurut Feri Djuandi (2011:8) "Komponen utama didalam papan Arduino adalah sebuah mikrokontroler 8 bit dengan merk ATmega yang dibuat oleh Atmel Corporation. Berbagai papan Arduino menggunakan tipe ATmega yang berbedabeda tergantung dari spesifikasinya., sebagai contoh Arduino Uno menggunakan ATmega328 sedangkan Arduino Mega 2560 yang lebih canggih menggunakan ATmega2560." [1]

Menurut Dwi Agus Diartono (2009:70) "Bluetooth adalah sebuah teknologi komunikasi wireless (tanpa kabel) yang beroperasi dalam pita frekuensi 2,4 $\mathrm{GHz}$ unlicensed ISM Industrial, Scientific and Medical) dengan menggunakan sebuah frequency hopping transceiver yang mampu menyediakan layanan komunikasi data dan suara secara real-time antara host-host Bluetooth dengan jangkauan layanan yang terbatas. ${ }^{[2]}$

Bluetooth adalah sebuah teknologi komunikasi wireless (tanpa kabel) yang beroperasi dalam pita frekuensi $2,4 \mathrm{GHz}$ unlicensed ISM Industrial, Scientific and Medical) dengan menggunakan sebuah frequency hopping transceiver yang mampu menyediakan layanan komunikasi data dan suara secara real-time antara host-host Bluetooth dengan jangkauan layanan yang terbatas.

Kesimpulannya adalah tekhnologi Bluetooth mampu menyediakan layanan komunikasi tanpa kabel berupa data dan suara serta jangkauan layanannya sangat terbatas tergantung dari frekuensinya.

Switch infrared sensor atau Adjustable infrared sensor adalah saklar atau sensor yang bekerja otomatis. Sensor IR atau infrared ini banyak digunakan sebagai aplikasi switch otomatis untuk aneka aplikasi.Sensor ini bekerja sebagai switch dengan jarak pengaktifan yang bisa diatur dari $3 \mathrm{~cm}$ sampai $80 \mathrm{~cm}$ lurus. dapat dipakai sebagai detektor pada robot untuk menghindari rintangan atau benda yang menghalangi sensor tersebut. Cara kerja sensor infrared pada dasarnya sama dengan cara kerja sensor pada umumnya, namun cara kerja sensor infrared dapat dilihat secara langsung ketika lampu dibelakan bagian sensor tidak menyala artinya sensor diberi kondisi $L O W$ ("0") dan ketika lampu dibagian belakang sensor menyala artinya sensor diberi kondisi $H I G H$ ("1"). ${ }^{[3]}$

Motor listrik merupakan perangkat elektromagnetis yang mengubah energi listrik menjadi energi mekanik. Pada dasarnya energi ini digunakan untuk memutar benda benda yang ada di sekitar kita, seperti untuk memggerakkan fan/kipas , menggerakan kompresor, mengangkat bahan,dan masih banyak yang lainnya.

Motor DC adalah jenis motor yang menggunakan tegangan DC (tegangan yang searah) sebagai sumber energi. Dengan memberikan tegangan yang berbeda di kedua terminal, motor akan berputar dalam satu arah, dan apabila polaritas tegangan dibalik maka arah putaran motor akan terbalik juga. ${ }^{[4]}$

IC L293D adalah $I C$ yang didesain khusus sebagai driver motor $D C$ dan dapat dikendalikan dengan rangkaian TTL maupun mikrokontroler. motor $D C$ yang dikontrol dengan driver IC L293D dapat dihubungkan ke ground maupun ke sumber tegangan positif karena di dalam driver L293D sistem driver yang digunakan adalah totem pool. Dalam 1 unit chip IC L293D terdiri dari 4 buah driver motor $D C$ yang berdiri sendiri sendiri 
dengan kemampuan mengalirkan arus 1 Ampere tiap driver. Sehingga dapat digunakan untuk membuat driver H-bridge untuk 2 buah motor $D C .{ }^{[4]}$

\section{KONSEP RANCANGAN}

Rancangan ini merupakan rancang bangun yang bertujuan untuk mendapatkan rancangan atau prototipe peralatan keamanan display toko perhiasan dan mengetahui kelayakan prototipe ini. Keamanan pada toko perhiasan dirancang melalui tahapan : analisa kebutuhan, desain blok diagram keamanan display pada toko perhiasan dan pengujian.

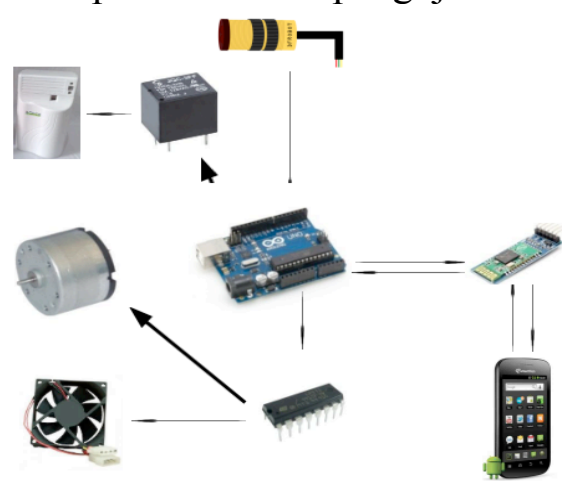

\section{Gambar 1. Diagram Blok Keamanan Pada Toko Perhiasan}

Desain diagram blok keamanan pada toko perhiasan terdiri dari blok input disini menggunakan sensor infrared dan smartphone yang sudah terinstal aplikasi blueterm, infrared ini digunakan untuk mengirimkan sinyal pada arduino untuk menggerakan motor dc yang akan menutup perhiasan kemudian semprotan akan menyemprotkan gas, untuk mengeluarkan gas yang ada dalam ruangan tersebut kita menggunakan kipas yang diaktifkan oleh bluetooth, ketika perhiasan masih tertutup oleh motor dc kita menggunakan bluetooth untuk memberikan perintah berupa karakter yang akan disampaikan oleh arduino pada motor dc untuk membukanya. Sistem kontrol yang digunakan adalah mikrokontroler Atmega 328 yang berada pada arduino.
Bentuk secara fisik peralatan pengaman berasal dari material akrilik dan papan. Didalam bok ini terdapat keseluruhan seperti rangkaian mekanik, device panunjang dan rangkaian keseluruhan perangkat keras yang di susun sesuai dengan fungsi dan kesesuaian rangkaian yang satu dengan yang lainnya agar terlihat rapi.

Pada rangcangan dibawah ini sudah dapat dilihat tata letak masing-masing mekanik, device penunjang dan perangkat keras yang diperlukan agar mudah dalam pemasangan, penggunaan dan rangkaian kabel yang teratur.

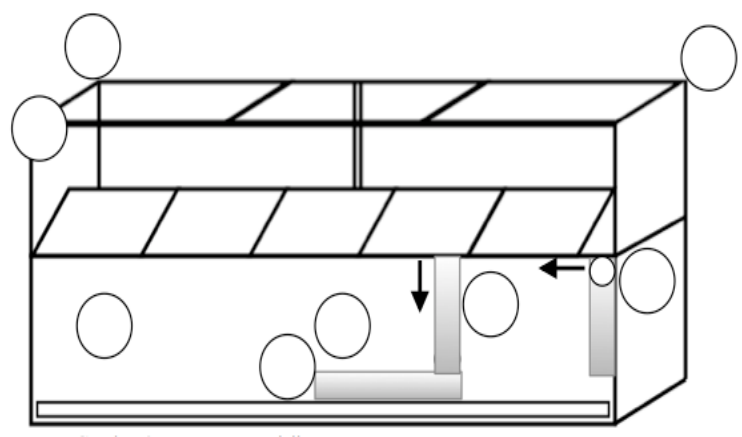

Gambar 2 Perancangan Fisik

Agar lebih mudah dalam memahami rancangan gambar 2 diatas dan cara kerjanya, dibawah ini merupakan tabel 3.1 keterangan dan penjelasannya.

\begin{tabular}{|l|l|l|}
\hline No & Nama & Keterangan \\
\hline 1 & $\begin{array}{l}\text { Area } \\
\text { Prototipe } \\
\text { Peralatan } \\
\text { Pengaman }\end{array}$ & $\begin{array}{l}\text { Area ini akan } \\
\text { diletakan device } \\
\text { pendukung dan } \\
\text { rangkaian. }\end{array}$ \\
\hline 2 & $\begin{array}{l}\text { Sensor } \\
\text { Infrared }\end{array}$ & $\begin{array}{l}\text { Sensor infrared } \\
\text { sebagai input untuk } \\
\text { penggerak motor dc. }\end{array}$ \\
\hline 3 & Motor DC & $\begin{array}{l}\text { Sebagai output } \\
\text { ketika rarar mensor } \\
\text { infrared menditeksi } \\
\text { gerakan maka motor } \\
\text { dc akan menarik } \\
\text { perhiasan kebawah } \\
\text { dan r menutup } \\
\text { perhiasan yang ada }\end{array}$ \\
\hline
\end{tabular}




\begin{tabular}{|c|c|c|}
\hline & & pada display. \\
\hline 4 & Arduino & $\begin{array}{l}\text { Sebagai pemberi } \\
\text { perintah, disini juga } \\
\text { terdapat rangkaian } \\
\text { iclegulator dan relay. }\end{array}$ \\
\hline 5 & Bluetooth & $\begin{array}{lr}\text { Sebagai } & \text { pemberi } \\
\text { perintah } & \text { untuk } \\
\text { menyalakan } & \text { kipas } \\
\text { dan mengeluarkan } \\
\text { gas } & \text { yang } \\
\text { disemprotkan dan } \\
\text { membuka kembali } \\
\text { tutup pelindung } \\
\text { perhiasan }\end{array}$ \\
\hline 6 & Semprotan & $\begin{array}{l}\text { Ketika } \text { sensor } \\
\text { infrared mediteksi } \\
\text { gerakan motor dc } \\
\text { menutup perhiasan } \\
\text { dan semprotan akan } \\
\text { menyemprotkan gas } \\
\text { air mata. }\end{array}$ \\
\hline 7 & Kipas & $\begin{array}{l}\text { ketika seluruh } \\
\text { ruangan berisi gas air } \\
\text { mata maka kipas ini } \\
\text { akan bergerak untuk } \\
\text { membuang gas } \\
\text { tersebut. }\end{array}$ \\
\hline
\end{tabular}

Program utama yang digunakan pada peralatan pengaman pada toko perhiasan adalah sebagai berikut :

int infrared $=\mathrm{A} 0$;

int val $=0$;

int $\operatorname{motor} 1 \operatorname{Pin} 1=3$;

int $\operatorname{motor} 1$ Pin $2=4$;

int enable1Pin $=6$;

int motor2Pin $1=8$;

int motor2Pin $=9$;

int enable2Pin $=11$;

int star;

int flag $=0$;

void $\operatorname{setup}()\{$
Serial.begin(9600);

pinMode(motor1Pin2, OUTPUT);

pinMode(enable1Pin, OUTPUT);

pinMode(motor2Pin1,OUTPUT);

pinMode(motor2Pin2, OUTPUT);

pinMode(enable2Pin, OUTPUT);

digitalWrite(enable1Pin, HIGH);

digitalWrite(enable2Pin, HIGH);

\}

void loop ()\{

val = digitalRead(infrared $)$;

if $($ val $==$ HIGH $)\{$

analogWrite(enable1Pin, 125);

digitalWrite(motor1Pin1, HIGH);

digitalWrite(motor1Pin2, LOW);

digitalWrite(motor2Pin1, LOW);

digitalWrite(motor2Pin2, LOW);

delay(50);

\}

else

\{

val = digitalRead(infrared $) ;$

if(val $==$ HIGH $)\{$

analogWrite(enable1Pin, 125);

digitalWrite(motor1Pin2, HIGH);

digitalWrite(motor1Pin1, LOW);

digitalWrite(motor2Pin2, LOW);

digitalWrite(motor2Pin1, LOW);

$\operatorname{delay}(50)$; 
\}

if $($ Serial.available ()$>0)\{$

state $=$ Serial.read ()$;$

flag $=0$;

\}

if $\left(\right.$ state $\left.=={ }^{\prime} a^{\prime}\right)\{$

analogWrite(enable1Pin, 125);

digitalWrite(motor1Pin1, LOW);

digitalWrite(motor1Pin2, HIGH);

digitalWrite(motor2Pin1, HIGH);

digitalWrite(motor2Pin2, HIGH);

if(flag $==0)\{$

flag=1;

\}

else if $\left(\right.$ state $\left.=={ }^{\prime} b '\right)\{$

analogWrite(enable1Pin, 125);

digitalWrite(motor1Pin2, LOW);

digitalWrite(motor1Pin1, HIGH);

digitalWrite(motor2Pin2, $\mathrm{HIGH}$ );

digitalWrite(motor2Pin1, HIGH);

if(flag $==0)\{$

flag $=1$;

\}

\}\}\}

Pengujian pada peralatan pengaman pada toko perhiasan berbasis arduino ini dilakukan dengan pengamatan pada ujuk kerja komunikasi sensor infrared dan bluetooth, pengujian alat dilakukan dengan dua pengujian, yaitu :

\section{Uji fungsional}

Pengujian ini dilakukan dengan cara menguji setiap bagian alat berdasarkan karakteristik dan fungsi masing-masing. Pengujian ini dilakukan untuk mengetahui apakah setiap bagian dari perangkat telah bekerja sesuai dengan fungsi dan keinginan

2. Uji unjuk kerja

Pengujian unjuk kerja alat dilakukan dengan cara melihat unjuk kerja alat. Hal-hal yang perlu diamati antara lain : jarak transmisi sensor dan pengujian listing program. Dari pengujian ini akan diketahui kenerja dari peralatan pengaman pada toko perhiasan.

\section{HASIL DAN PEMBAHASAN}

Tujuan dari pengujian adalah untuk mengetahui kenerja alat.

\section{Hasil pengujian}

1. Pengujian jarak transmisi sensor infrared dan bluetooth

a) Free Space

Pengukuran jarak transmisi bertujuan untuk mengetahui seberapa jauh sensor infrared dan bluetooth dapat terhubungan dan mampu menerima dan membawa perintah ke mikrokontroler.

Tabel 1. Pengujian jarak transmisi free

\begin{tabular}{|l|l|l|l|l|l|}
\hline $\begin{array}{l}\text { Sensor } \\
\text { Infrare } \\
\mathrm{d}\end{array}$ & & $\begin{array}{l}\text { Bluetoot } \\
\mathrm{h}\end{array}$ & & \\
\hline Jarak & Hasil & $\begin{array}{l}\mathrm{Wa} \\
\mathrm{ktu} \\
(\mathrm{de} \\
\text { tik })\end{array}$ & Jarak & Hasil & $\begin{array}{l}\text { Wak } \\
\text { tu } \\
(\text { deti } \\
\mathrm{k})\end{array}$ \\
\hline $10 \mathrm{~cm}$ & Lancar & 1 & 1 meter & Lancar & 1 \\
\hline $20 \mathrm{~cm}$ & Lancar & 1 & 2 meter & Lancar & 1 \\
\hline $30 \mathrm{~cm}$ & Lancar & 1 & 3 meter & Lancar & 1 \\
\hline $40 \mathrm{~cm}$ & Lancar & 1 & 4 meter & Lancar & 1 \\
\hline $50 \mathrm{~cm}$ & Lancar & 1 & 5 meter & Lancar & 1 \\
\hline $60 \mathrm{~cm}$ & Lancar & 1 & 6 meter & Lancar & 1 \\
\hline $70 \mathrm{~cm}$ & Lancar & 1 & 7 meter & Lancar & 1 \\
\hline $80 \mathrm{~cm}$ & Lancar & 1 & 8 meter & Lancar & 1 \\
\hline
\end{tabular}




\begin{tabular}{|l|l|l|l|l|l|}
\hline $90 \mathrm{~cm}$ & $\begin{array}{l}\text { Tidak } \\
\text { merespo } \\
\mathrm{n}\end{array}$ & - & 9 meter & $\begin{array}{l}\text { Konek } \\
\text { si } \\
\text { terputu } \\
\mathrm{s}\end{array}$ & - \\
\hline
\end{tabular}

b) Indoor (banyak benda disekitar alat)

Tabel 2. Pengujian jarak transmisi indoor banyak benda disekitar alat

\begin{tabular}{|l|l|l|l|l|l|}
\hline $\begin{array}{l}\text { Sensor } \\
\text { dnfrare }\end{array}$ & & & $\begin{array}{l}\text { Bluetoot } \\
\mathrm{h}\end{array}$ & & \\
\hline Jarak & $\begin{array}{l}\mathrm{H} \\
\mathrm{a} \\
\text { s } \\
\mathrm{i}\end{array}$ & $\begin{array}{l}\text { Wak } \\
\text { tu } \\
\text { k) }\end{array}$ & Jarak & Hasil & $\begin{array}{l}\text { Waktu } \\
\text { (detik) }\end{array}$ \\
& 1 & & & & \\
\hline- & - & - & 1 meter & Lancar & 1 \\
\hline- & - & - & 2 meter & Lancar & 1 \\
\hline- & - & - & 3 meter & Lancar & 1 \\
\hline- & - & - & 4 meter & Lancar & 1 \\
\hline- & - & - & 5 meter & Lancar & 1 \\
\hline- & - & - & 6 meter & Lancar & 1 \\
\hline- & - & - & 7 meter & $\begin{array}{l}\text { Konek } \\
\text { si } \\
\text { terputu } \\
\text { s }\end{array}$ & 1 \\
\hline & & & & & \\
\hline
\end{tabular}

\section{PEMBAHASAN}

1. Perangkat keras (Hardware)

a) Power Supply

Power supply adalah sumber daya yang digunakan untuk memasok tegangan pada semua komponenyang terdapat pada alat. Power supply disini terdiri dari trafo, diode, kapasitor dan regulator 7805. Power supply pada alat ini menghasilkan tegangan 12 Volt. Dengan tegangan tersebut sudah bisa memasok semua komponen yang digunakan pada alat.

b) Sensor infrared

Sensor infrared adalah saklar atau sensor yang bekerja otomatis. Sensor IR atau infrared ini banyak digunakan sebagai aplikasi switch otomatis untuk aneka aplikasi.Sensor ini bekerja sebagai switch dengan jarak pengaktifan yang bisa diatur dari $3 \mathrm{~cm}$ sampai $80 \mathrm{~cm}$ lurus. dapat dipakai sebagai detektor pada robot untuk menghindari rintangan atau benda yang menghalangi sensor tersebut.

c) Bluetooth

Bluetooth merupakan teknologi yang bisa menghubungkan dua perangkat elektronik seperti PC ke handphone. Dapat mengirimkan data tanpa menggunakan kabel dan tidak memerlukan saluran koneksi yang terlihat. Pada alat ini smartphone digunakan sebagai pemeberi perintah/input dan bluetooth yang mengkomunikasikan perintah tersebut pada sistem mikrokontroler. Bluetooth yang digunakan adalah Modul Bluetooth HC-06.

d) Arduino

Arduino adalah multi platform open source software. Arduino dapat dijalankan pada linux, windows atau juga mac. Pada alat ini arduino dijalankan menggunakan windows. Bahasa pemrograman yang digunakan pada arduino adalah bahasa $\mathrm{C}$, tetapi arduino sudah lebih dipermudah dengan fungsi yang sederhana. Dengan menggunakan aplikasi amarino dan software Arduino yang diterapkan pada pembuatan pengendali pintu gerbang, ini dapat berfungsi dengan bail dibuktikan dengan algoritma yanng terdiri atas :
(1) Program inisialilasi,
(2) program setup,
(3) program scanning dan
(4) program masukan.

Sudah berfungsi sesuai program dan alat sudah dapat beroperasi.

e) Sistem mikrokontroler Atmega328

Sistem mikrokontroler ATmega328 adalah gabungan dari beberapa komponen yang 
difungsikan sebagai pengendali pada alat ini. Gabungan dari beberapa komponen ini disebut juga sistem minimum. Ada beberapa faktor pertimbangan mengapa pada alat ini menggunakan ATmega328, diantaranya: harganya murah, banyak dipasaran, dan sudah memenuhi yang dibutuhkan oleh alat. Sistem mikrokontroler ATmega328 ini sudah bisa memproses data perintah dan menerjemahkan perintah tersebut untuk dijadikan gerakan pada motor de sebagai buka-tutup pengaman perhiasan. Ini menunjukan sistem pada mikrokontroler Atmega328 sudah bisa beroperasi dengan baik.

f) Motor DC

Motor DC adalah jenis motor yang menggunakan tegangan DC (tegangan yang searah) sebagai sumber energi. Dengan memberikan tegangan yang berbeda di kedua terminal, motor akan berputar dalam satu arah, dan apabila polaritas tegangan dibalik maka arah putaran motor akan terbalik juga.

g) IC $\mathrm{L} 293 \mathrm{D}$

IC L293D adalah IC yang didesain khusus sebagai driver motor $D C$ dan dapat dikendalikan dengan rangkaian TTL maupun mikrokontroler. motor $D C$ yang dikontrol dengan driver IC L293D dapat dihubungkan ke ground maupun ke sumber tegangan positif karena di dalam driver L293D sistem driver yang digunakan adalah totem pool. Dalam 1 unit chip IC L293D terdiri dari 4 buah driver motor $D C$ yang berdiri sendiri sendiri dengan kemampuan mengalirkan arus 1 Ampere tiap driver. Sehingga dapat digunakan untuk membuat driver H-bridge untuk 2 buah motor $D C$.

2. Perangkat lunak (software)

a) IDE Arduino adalah software yang beroperasi di komputer, disebut juga Arduino Software. Tugasnya adalah menghasilkan sebuah file berformat hex yang akan di download pada papan arduino yang menghasilkan program dari kode bahasa C, IDE Arduino menghasilkan file hex dari baris kode yang disebut sketch.

a) Blueterm adalah program apliaksi yang digunakan pada smartphone sebagai command pembuat perintah/input yang terinstal pada smartphone. Blueterm sudah dapat berfungsi dengan baik dibuktikan dengan alat yang mampu beroperasi sesuai program.

3. Unjuk kerja

Hardware dan Software telah berfungsi dengan baik ini dibuktikan dengan alat yang mampu beroperasi sesuai dengan program dan perintah yang dimasukan. Melihat dari data pengukur transmisi distance sensor dan bluetooth dapat merespon dengan jarak sensor $80 \mathrm{~cm}$ dan bluetooth dapat dikendalikan dengan jarak maksimal 8 meter serta 6 meter apabila banyak alat/ penghalang disekitar alat. Dengan demikian dapat disimpulkan rancang bangun peralatan pengaman toko perhiasan berbasis arduino ini sudah dapat beroperasi, hal ini dibuktikan dengan sesuainya antara kode perintah dengan hasil eksekusi kinerja peralatan perngaman toko perhiasan.

\section{KESIMPULAN}

Berdasarkan hasil pengujian yang telah dilakukan terhadap Rancang Bangun 
Peralatan Pengaman Berbasis Arduino disimpulkan sebagai berikut :

1. Hardware terdiri dari gabungan sensor sebagai input (pemberi perintah), motor DC sebagai output penggerak untuk menutup perhiasan, semprotan sebagai alat untuk menyemprotkan gas, modul bluetooth sebagai perantara perintah untuk membuka kembali perhiasan yang tertutup sekaligus dapat menyalakan kipas penyedot gas pada ruang toko.

2. Merealisasikan pembuatan software peralatan pengaman yang terdiri atas : (1) program inisialisasi yaitu program untuk menginialisasi variable, (2) setup program yaitu program untuk memasukan pin yang diinginkan sebagai output, (3) program scanning yaitu program untuk memindai perintah yang dimasukan (4) program masukan yaitu program untuk menentukan karakter kode yang akan digunakan sebagai masukan. Semua program tersebut sudah dapat berfungsi.

3. Unjuk kerja peralatan pengaman ini dapat merespon gerak pada sensor infrared dengan maksimum adalah $80 \mathrm{~cm}$, dan bluetooth dengan jarak maksimum 8 meter, 6 meter pada ruang yang terdapat banyak benda disekitar alat.

\section{DAFTAR PUSTAKA}

1. Feri Djuandi. 2011. "Pengenalan Arduino". E-book. www.tobuku, Juli 2011

2. Dwi Agus Diartono. 2009. Teknologi Bluetooth untuk Layananan Internet pada Wireless Local Area Network. Jurnal Teknologi Informasi DINAMIK. Semarang. Vol. XIV, pp. 70-78. (Januari 2009).

3. C. F. Tsai and M. S. Young . "Pyroelectric infrared sensor-based thermometer for monitoring indoor objects". Review of Scientific Instruments 74 (12): $\quad 5267-$ 5273.doi:10.1063/1.1626005.

4. http://elektronika-dasar.web.id diakses pada tanggal 12-09-2014

5. Simarmata, Janner. 2010. REKASA PERANGKAT LUNAK. Yogyakarta: C.V ANDI OFFSET.

6. Wiyancoko, Dudy. 2010. Desain Sepeda Indonesia. Jakarta: PT Dumedia Desain.

7. Yonatan Ari Sulistia Adi, Titin Winarti, dan Vensy Vydia. 2012. Aplikasi Pengenalan Objek Pariwisata Kalimantan Pada Mobil Smartphone Berbasis Andrid2.2. Jurnal TransIT. Kalimantan. Vol. 1, pp.1-15 (januari 2012). 